\title{
Digital Game-Based Teaching in Visual Basic Program Design of Agricultural Universities:Application and Impact on Education Effectiveness
}

\author{
Zhao Chen \\ College of science and information \\ Qingdao Agricultural University \\ Qingdao, China \\ zhao918chen@163.com
}

\author{
Huang Fang* \\ College of foreign language \\ Qingdao Agricultural University \\ Qingdao, China \\ huang311fang@163.com
}

\begin{abstract}
Visual Basic program design is a required course in Chinese agricultural universities. Considering the professional uniqueness of university students, digital game-based teaching method has been applied in the course of Visual Basic program design. The education effectiveness of the digital game-based teaching was analyzed in a survey with 282 participants in Qingdao Agricultural University. The research results show that digital game-based teaching is significantly effective in improving students' learning outcomes of Visual basic program design.
\end{abstract}

Keywords-digital game-based teaching; Visual Basic program design; education effectiveness;

\section{INTRODUCTION}

Visual Basic program design is an important foundation course in computer science. It is also one of the examination languages in National Computer Rank Examination in China. As a required course, it proves to be very difficult for university students in China, take students from Qingdao Agricultural University for example; the passing rates have been low for years (average 75\%). Large quantities of complicated concepts, controls, as well as complex and changeable events are hard to be learned effectively for students without basic programming practices. This research aims to assess the education effectiveness of the digital game-based teaching method adopted in the course of Visual Basic program design, considering education problems and difficulties in agricultural universities in China.

\section{CURRENT SITUATION IN VisUal BASIC PROGRAM DESIGN EDUCATION}

\section{A. Professional uniqueness of students in agricultural universities}

Students from agricultural universities are quite different from students of regular universities in terms of their professions and specialties. Agriculture-related courses make education be featured by significant emphases on practices and trainings of operational abilities. Thus, students' learning styles are more kinesthetic and tactical, which means students benefit from doing objects, working with objects, and moving around, such as, some games conducting experiments ${ }^{[1]}$. Students of agricultural universities are increasingly proved to be negative in the seemingly boring learning of some theoretical knowledge, but very positive and highly motivated in vivid examples and practices. It is found by years of teaching experiences that designing vivid and lively digital games can arouse students' motivations and improve their learning effectiveness by students' involvements ${ }^{[2]}$.

\section{B. Problems in Visual Basic program design education}

Originated from America in the 1960's, Basic language is the abbreviation of Beginner's All-Purpose Symbolic Instruction Code, which is widely used due to its advantages including easiness to learn, flexibility of man-machine conversation, and convenience of program run debugging ${ }^{[3]}$. In Chinese agricultural universities, the learning objective is mainly Visual Basic 6.0, which is characterized by the visualized programming tool, object-oriented design, component programming, structured programming language, event-driven programming. Compared with traditional programming designs, it makes students feel hard to learn effectively. Some problems are stated as follows:

First, object-oriented design is a new design philosophy which is different from traditional programming in terms of its unique mode of thinking. Students are more accustomed to sequential structure in programming and they take it for granted that a program is supposed to be started by main function, and be ended by one line of code. The difficulty in understanding the core idea of object-oriented design makes the main problem for students at the beginning stage in learning the course of Visual Basic program design ${ }^{[4]}$.

Second, there are quantities of complicated concepts in Visual Basic 6.0. As far as the visualized object-oriented program design is considered, it contained a great many new concepts, such as object, category or class, attribute, event, method. Students have to not only get their rote memories for these complicated concepts, but also analyze and understand the meanings of these concepts, on the basis of mastering the core ideas of object-oriented program. Therefore, game-based examples are quite needed for the education effectiveness.

Third, it is complicated in terms of controls and events. Visual Basic 6.0 provides plenty of controls, including many basic controls and the extensible ActiveX control, which are important carriers for object-oriented program 
design. Proficiencies of these controls help to effectively improve students' flexibilities in programming process. Unfortunately these controls are proved to be obstacles for the beginners. Understanding and mastering the use of each control are preconditions, and they can be further experienced and mastered by examples and program writing. Event-driven programming is adopted in Visual Basic 6.0 and it is considered as a breakthrough of traditional programming thinking. Program run and event are closely related. The same program operated by different users can produce different operational procedures and computational results. Some of events are related to mouse and keyboard, for example, Mouse Up, Mouse Down, Key Up, Key Down and Key Press, etc. How to master these events are important problems for the beginners of Visual Basic 6.0.

\section{TEACHING PEDAGOGY}

\section{A. Student-oriented pedagogy}

Students, especially students in agricultural universities, believe learning program design has nothing to do with their majors, thus, they are lack of learning interests and negatively motivated in learning process. However, they show great interests in digital games, and even those simple and boring games can attract their attention. Therefore, digital game-based teaching which is in accordance with student-oriented theory can improve students learning motivation and learning proficiency.

\section{B. Teachers' instruction}

Implying interesting digital games which contain boring concepts, controls and events to the class teaching of Visual Basic program design can increase the education enjoyment and students' involvements. In the digital game programming process, some incomplete details are suggested to be designed by teachers, with the intention to encourage students to perfect these details themselves during practice. This design of teacher's instruction is helpful to enhance students' learning of essences in the programming, which is object-oriented and event-driven programming, through their own practices. At last, the mastering a whole development process of software system can be easily achieved.

\section{IMPlement of Digital GAme-BASEd TeAching}

Digital game is a kind of amusement that is achieved by one or more person following certain rules. Nowadays, games have been adopted widely as pedagogies in different fields, and have formed an innovative mode of teaching, which is called digital game-based teaching. Games are used as media to deliver contents of courses(Conati, 2002) ${ }^{[5]}$. Digital game-based teaching is effective to divert boring learning and knowledge to the very vivid and interesting games through students' involvements of some designed pleasant activities and fierce competitions. According to Marina Papastergiou (2009), the game-based approach was both more effective in promoting students' knowledge of computer memory concepts and more motivational than the non-game-based approach ${ }^{[6]}$. This research put forward the implement of the digital game-based teaching to Visual Basic program design. This method can not only stimulate students' motivation, but also change traditional rote memory learning method, and it helps to active learning atmosphere in class as well. The intentionally designed incomplete details in games can also help to provoke students' potential abilities in development procedures.

\section{A. Kitten fishing game design}

At first, the game rules and the interfacial design were discussed by teachers and students, and then the required controls in the game design as well as the general design thought were determined. Later, teachers demonstrate the prepared kitten fishing digital game using the multi-media device. The constantly emerging fishes and fishing poles are sure to attract students' attention. The interface of congratulations is showed immediately after fishes are caught, and expression of the kitten also changes soon afterwards. Game scores are calculated after playing for a while. At last, students are required to explain which controls and events are used in the digital game, and then new knowledge can be led in.

\section{B. Operation of kitten fishing game}

Set up a kitten fishing project and design the background picture, then add 11 controls of Picture Box to it, and set attribute of Auto Size as True, with one fish tank, one kitten, others for fishes.

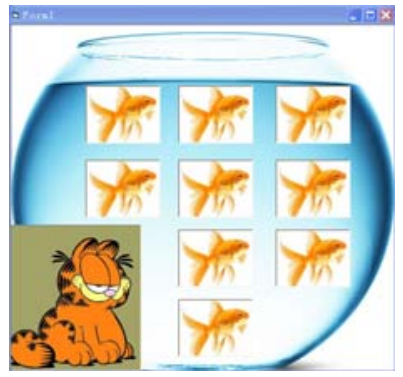

Figure1. Surface chart of game with pictures

Later, add Timer control to let fishes emerge randomly. Attributes and uses of Timer control are explained. Set Enabled control to be True, Interval as 1000, that is to say, a fish will emerge every other second. Explain the arithmetic to generate random number in a certain limit, the key statement is:

$$
\mathrm{i}=1+\mathrm{int}\left(\operatorname{rnd}()^{*} 9\right)
$$

In this statement, the " $i$ " is a random integer from 1-9. Select Case i statement is used to realize fishes' emergence and hide. PictureBox1-PictureBox 9 is the control for 9 fishes. Take $\mathrm{i}=5$ for instance: 


\section{Case 5}

PictureBox1.Hide()

PictureBox2.Hide()

PictureBox3.Hide()

PictureBox4.Hide()

PictureBox5.Show()

PictureBox6.Hide()

PictureBox7.Hide()

PictureBox8.Hide()

PictureBox9.Hide()

\section{Further perfection}

The basic framework of the digital game "kitten fishing" has been completed, but some functions are to be perfected. Students are encouraged and inspired to give full play to their imagination and to perfect the game using knowledge they learned. For example, add background music; using diversified vivid pictures to show different possible fishing outcomes; increase or add global variable to calculate how many fishes kitten got; add timing function and set count down; add adjust modules to adjust fishes' emerging frequency.

In the teaching practices, it is very necessary to cut some additional functions considering students' responses, in case of students' negative attitudes to the difficulties. The ultimate purpose for digital game-based teaching is to arouse students' learning motivation, lead them to the proper effective learning strategies, provoke their imaginations, and make the game perfect using accumulated knowledge through students' efforts. Students' sense of achievement and satisfaction can in turn benefit their learning motivations for further study to a large degree.

\section{Methodology}

To assess and evaluate the education effectiveness of the digital game-based teaching, a research has been conducted in the course of Visual Basic program design in Qingdao Agricultural University.

\section{A. Participants}

Class A (the experimental class) and Class B (the control class) in Qingdao Agricultural University are randomly chosen by researchers. Students in the two classes are freshmen and they all major in Animal Medicine. Students in the two classes are taught by different teaching methods by the same teacher. All the 145 students in class A (experimental class) are taught with the method of digital game-based teaching, and all the 137 students in class B (control class) are taught by the traditional teaching method, without involving digital game-based teaching. At the end of the term, all the participants in this research are required to fill in the items in a designed questionnaire, and their scores are needed also.

\section{B. Questionaire Design and Data Collection}

All the items in the questionnaire are designed based on characteristics of digital game-based teaching using Likert scale. The main items contain: (1) whether the teaching method strengthen learning motivation; (2) whether teachers' demonstration can positively guide students in the digital game-based teaching; (3) whether the digital game based teaching reinforce the understanding of complicated concepts; (4) whether the digital game-based teaching reduce learning difficulty; (5) whether the digital game-based teaching helps to improve programming ability.

All the participants in class A (145 students) are required to fill in all items within 30 minutes at the same time, in the same place. Then, researchers in the study collect all the questionnaires..

\section{RESUlTS}

After careful examination, 132 questionnaires are valid, and all the valid data are analyzed using SPSS 13.0 software. The results show that $68.87 \%$ of participants in the experimental class think their motivations have been strongly strengthened; $58.25 \%$ of them strongly agree with teachers' demonstration positively guide students; $78.67 \%$ of them strongly agree with game-based teaching's reinforcement of students' understanding; $45.67 \%$ of them feel their learning difficulties have been reduced; and $88.90 \%$ of them strongly agree that their programming abilities have been improved.

TABLE ONE EDUCATION EFFECTIVENESS OF DIGITAL GAMEBASED TEACHING

\begin{tabular}{|c|c|c|c|}
\hline Items & Scales & Results (\%) & weight \\
\hline \multirow{5}{*}{$\begin{array}{l}\text { Strengthen } \\
\text { learning } \\
\text { motivation }\end{array}$} & A. strongly agree & 68.87 & \multirow{5}{*}{$\delta_{1}$} \\
\hline & B. agree & 17.67 & \\
\hline & C. not certain & 8.32 & \\
\hline & D. disagree & 5.14 & \\
\hline & E. strongly disagree & 0 & \\
\hline \multirow{5}{*}{$\begin{array}{l}\text { Teacher's } \\
\text { demonstration } \\
\text { positively guide } \\
\text { students }\end{array}$} & A. strongly agree & 58.25 & \multirow{5}{*}{$\delta_{2}$} \\
\hline & B. agree & 20.41 & \\
\hline & C. not certain & 14.32 & \\
\hline & D. disagree & 7.02 & \\
\hline & E. strongly disagree & 0 & \\
\hline \multirow{5}{*}{$\begin{array}{l}\text { Reinforce the } \\
\text { understanding of } \\
\text { complicated } \\
\text { concepts }\end{array}$} & A. strongly agree & 78.67 & \multirow{5}{*}{$\delta_{3}$} \\
\hline & B. agree & 12.65 & \\
\hline & C. not certain & 6.27 & \\
\hline & D. disagree & 2.41 & \\
\hline & E. strongly disagree & 0 & \\
\hline \multirow{5}{*}{$\begin{array}{l}\text { Reduce learning } \\
\text { difficulty }\end{array}$} & A. strongly agree & 45.67 & \multirow{5}{*}{$\delta_{4}$} \\
\hline & B. agree & 31.33 & \\
\hline & C. not certain & 20.15 & \\
\hline & D. disagree & 2.85 & \\
\hline & E. strongly disagree & 0 & \\
\hline \multirow{5}{*}{$\begin{array}{l}\text { Improve } \\
\text { programming } \\
\text { ability }\end{array}$} & A. strongly agree & 88.90 & \multirow{5}{*}{$\delta_{5}$} \\
\hline & B. agree & 9.03 & \\
\hline & C. not certain & 1.38 & \\
\hline & D. disagree & 0.69 & \\
\hline & E. strongly disagree & 0 & \\
\hline
\end{tabular}


Participants are required to choose weight levels among the most important, important and less important. Using multi-factor statistics, researchers statistically calculate the results and determine $\delta$ according to the $\mathrm{Wi}$. The results are: $\delta_{1}=0.45, \quad \delta_{2}=0.07, \quad \delta_{3}=0.15, \quad \delta_{4}=0.12, \quad \delta_{5}=0.21$.

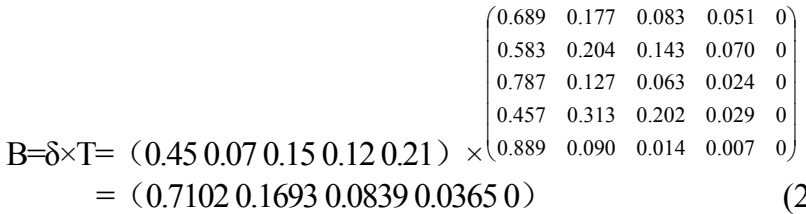

The results show that students who have very good feedbacks for digital game-based teaching take up 71.02\%, $16.93 \%$ of them have good feedbacks. In a word, the digital game-based teaching has been proved to be welcome in Visual Basic program design.

For further evaluation of the education effectiveness of digital game-based teaching, students' testing scores in class $\mathrm{A}$ and class $\mathrm{B}$ have been analyzed. The mean of testing scores in class $\mathrm{A}$ is higher than that in class $\mathrm{B}$. The significance is 0.002 , which indicates the testing scores of class A and class B is significantly different.

TABLE II TESTING SCORES

\begin{tabular}{|c|c|c|c|c|c|c|}
\hline CLASS & $\mathbf{N}$ & MEAN & SD & DF & t & $\begin{array}{c}\text { SIGNIFICANCE } \\
\text { LEVEL( } \alpha \text { ) }\end{array}$ \\
\hline A & 145 & 75.58 & 8.65 & & & \multirow{2}{*}{60} \\
B & 137 & 69.91 & 9.32 & & & $0.002 *$ \\
\hline
\end{tabular}

\section{DISCUSSION}

Based on the above research findings, conclusions are as follows:

First, students' study interests and motivation are of great importance in Visual Basic program design. The weight coefficient of motivation is the biggest. After adopting digital game-based teaching in Visual Basic program design, $86.54 \%$ of participants believe their motivation have been increased, and thus their study initiative have been also increased. In the daily teaching process, instructors and teachers are supposed to study students' motivation and adopt the effective teaching methods so as to improve learning proficiency.

Second, Teachers should also consider students' individual differences, especially their learning style preferences. Also, students in agricultural universities come from different cities, a large number of them come from remote rural areas in China, where the educational levels are far behind than cities. Therefore, the basic knowledge of students varies to a large degree. For some students who are poor in this course, group learning or cooperative learning is suggested for them to achieve co-progress.

Third, since $88.90 \%$ of all the participants believe digital game-based learning helps to improve programming abilities, teachers may encourage students to involve themselves into the real programming process which benefits their cognition and operational abilities.

The research has been conducted among 282 participants from the same major in Qingdao Agricultural University. The number of participants is kind of limited. Later, for further investigate education effectiveness of the digital game-based teaching method, more students from different majors in different agricultural universities are supposed to take part in this research.

\section{ACKNOWLEDGMENT}

Sincere Thanks will be expressed to my family members and my colleagues who make great efforts in questionnaire design and collection. Without their devotion, this paper will not be a success and be delivered in due time for 2013 International Conference on Education Technology and Management Science. .

\section{REFERENCES}

[1] Huang Fang, "Gender Difference in learning style," Science and Technology Information, vol. 19, 2008, pp.221.

[2] Zhang xiaolian, Zhang yuandeng, "On application and effect of game teaching in management courses of higher vocational Education," Journal of Wuhan Polytechnic, vol. 9, 2010, pp. 78.

[3] Ye xiangmei, "Teaching VB course for non-computer majors in higher vocational colleges," Journal of Zhejiang Business Technology Institute,vol.9, 2010, pp. 81.

[4] Li yanzhao, Yu Hua, Visual Basic Program Design, China Agriculture Press, 2011, pp.1.

[5] Conat1, C. "Probabilistic assessment of user's emotions in educational games," Journal of Applied Artificial Intelligence"Merging Cognition and Affect in HCI", 2002.

[6] Marina Papastergiou, "Digital Game-Based Learning in high school Computer Science education: Impact on educational effectiveness and student motivation." Computers \& Education, vol. 52, 2009, pp.1. 